\title{
Cutaneous Metastases
} Masquerading as Solitary or
Multiple Keratoacanthomas

Philip R. Cohen, MD; Ryan R. Riahi, MD

\section{To the Editor:}

We read with interest the excellent Cutis articles on cutaneous metastases by Tarantino et $\mathrm{al}^{1}$ and Agnetta et al. ${ }^{2}$ Tarantino et $\mathrm{al}^{1}$ reported a 59 -year-old man who developed cutaneous metastases on the scalp from an esophageal adenocarcinoma. Agnetta et $\mathrm{al}^{2}$ described a 76-year-old woman with metastatic melanoma mimicking eruptive keratoacanthomas.

Cutaneous metastases are not common. They may herald the unsuspected diagnosis of a solid tumor recurrence or progression of systemic disease in an oncology patient. Occasionally, they are the primary manifestation

Dr. Cohen is from San Diego Family Dermatology, National City, California, and Touro University California College of Osteopathic Medicine, Vallejo. Dr. Riahi is from DermSurgery Associates, Sugar Land, Texas.

The authors report no conflict of interest.

Correspondence: Philip R. Cohen, MD, 10991 Twinleaf Ct, San Diego, CA 92131-3643 (mitehead@gmail.com). 
of a visceral tumor in a previously cancer-free patient. Less often, skin lesions are the manifestation of a new or recurrent hematologic malignancy.,

The morphology of cutaneous metastases is variable. Most commonly they appear as papules and nodules. However, they can mimic bacterial (eg, erysipelas) and viral (eg, herpes zoster) infections or present as scalp alopecia.. . $^{5-7}$

Cutaneous metastases also can mimic benign (eg, epidermoid cysts) or malignant (eg, keratoacanthoma) neoplasms. Keratoacanthomalike cutaneous metastases are rare. ${ }^{8}$ They can present as single or multiple tumors. ${ }^{9,10}$

In the case reported by Tarantino et $\mathrm{al}^{1}{ }^{1}$ the patient had a history of metastatic adenocarcinoma of the esophagus. His unsuspected recurrence presented not only with a single keratoacanthomalike cutaneous metastasis on the scalp but also with another metastasis-related scalp lesion that appeared as a smooth pearly papule. We also observed a 53-year-old man whose metastatic esophageal adenocarcinoma presented with a keratoacanthomalike nodule on the right upper lip; additionally, the patient had other cutaneous metastases that appeared as an erythematous papule on the forehead and a cystic nodule on the scalp. ${ }^{8}$ Other investigators also observed a single keratoacanthomalike lesion on the left cheek of a 49-yearold man with metastatic esophageal adenocarcinoma. ${ }^{11}$

Agnetta et $\mathrm{al}^{2}$ described a patient with a history of malignant melanoma on the left upper back that had been excised 2 years prior. She presented with the eruptive onset of multiple keratoacanthomalike cutaneous metastases on the chest, back, and right arm. ${ }^{2}$ The important observation of metastatic malignant melanoma presenting as multiple keratoacanthomalike cutaneous metastases pointed out by Agnetta et $\mathrm{al}^{2}$ confirms a similar occurrence reported by Reed et $\mathrm{al}^{12}$ in a patient with metastatic malignant melanoma.

We also previously reported the case of a 68-year-old man with metastatic laryngeal squamous cell carcinoma (SCC) who developed more than 10 keratoacanthomalike nodules within a radiation port that extended from the face to the mid chest. ${ }^{10}$ In addition, other researchers have noted a similar phenomenon of keratoacanthomalike cutaneous metastases mimicking eruptive keratoacanthomas. ${ }^{13}$ Gil et $a 1^{14}$ described a 40 -year-old woman whose metastatic epithelioid trophoblastic tumor initially presented as 11 keratoacanthomalike scalp nodules; interestingly, the first nodule spontaneously regressed. Araghi et $\mathrm{al}^{15}$ reported a 58-year-old woman-with a stable SCC of the larynx that had been diagnosed 2 years prior and treated with chemoradiotherapy-in whom cancer progression presented as multiple keratoacanthomalike lesions in an area of prior radiotherapy.
In conclusion, cutaneous metastases presenting as new-onset solitary or multiple keratoacanthomalike nodules in either a cancer-free individual or a patient with a prior history of a visceral malignancy is uncommon. Although the clinical features mimic those of a single or eruptive keratoacanthomas, a biopsy will readily establish the diagnosis of cutaneous metastatic cancer. Metastatic esophageal carcinoma - either adenocarcinoma or SCCcan present, albeit rarely, with cutaneous lesions that can have various morphologies. ${ }^{8}$ Whether there is an increased predilection for patients with metastatic esophageal adenocarcinoma to present with single keratoacanthomalike cutaneous metastases with or without concurrent additional skin lesions of cutaneous metastases of other morphologies remains to be determined.

\section{REFERENCES}

1. Tarantino IS, Tennill T, Fraga G, et al. Cutaneous metastases from esophageal adenocarcinoma on the scalp. Cutis. 2020;105:E3-E5.

2. Agnetta V, Hamstra A, Hirokane J, et al. Metastatic melanoma mimicking eruptive keratoacanthomas. Cutis. 2020;105:E29-E31.

3. Cohen PR. Skin clues to primary and metastatic malignancy. Am Fam Physician. 1995;51:1199-1204.

4. Cohen PR. Leukemia cutis-associated leonine facies and eyebrow loss. Cutis. 2019;103:212.

5. Cohen PR, Prieto VG, Piha-Paul SA, et al. The "shield sign" in two men with metastatic salivary duct carcinoma to the skin: cutaneous metastases presenting as carcinoma hemorrhagiectoides. J Clin Aesthet Dermatol. 2012;5:27-36.

6. Manteaux A, Cohen PR, Rapini RP. Zosteriform and epidermotropic metastasis. report of two cases. J Dermatol Surg Oncol. 1992;18:97-100.

7. Conner KB, Cohen PR. Cutaneous metastases of breast carcinoma presenting as alopecia neoplastica. South Med J. 2009;102:385-389.

8. Riahi RR, Cohen PR. Clinical manifestations of cutaneous metastases: a review with special emphasis on cutaneous metastases mimicking keratoacanthoma. Am J Clin Dermatol. 2012;13:103-112.

9. Riahi RR, Cohen PR. Malignancies with skin lesions mimicking keratoacanthoma. Dermatol Online J. 2013;19:20397.

10. Ellis DL, Riahi RR, Murina AT, et al. Metastatic laryngeal carcinoma mimicking eruptive keratoacanthomas: report of keratoacanthoma-like cutaneous metastases in a radiation port. Dermatol Online J. 2014;20. pii:13030/qt3s43b81f.

11. Hani AC, Nuñez E, Cuellar I, et al. Cutaneous metastases as a manifestation of esophageal adenocarcinoma recurrence: a case report [published online September 5, 2019]. Rev Gastroenterol Mex. doi:10.1016/j. rgmx.2019.06.002.

12. Reed KB, Cook-Norris RH, Brewer JD. The cutaneous manifestations of metastatic malignant melanoma. Int J Dermatol. 2012;51:243-249.

13. Cohen PR, Riahi RR. Cutaneous metastases mimicking keratoacanthoma. Int J Dermatol. 2014;53:E320-E322.

14. Gil F, Elvas L, Raposo S, et al. Keratoacanthoma-like nodules as first manifestation of metastatic epithelioid trophoblastic tumor. Dermatol Online J. 2019;25. pii:13030/qt9xx6p2tt.

15. Araghi F, Fatemi A, Rakhshan A, et al. Skin metastasis of laryngeal carcinoma presenting as multiple eruptive nodules [published online February 10, 2020]. Head Neck Pathol. doi:10.1007/ s12105-020-01143-1. 